\title{
Selective laser sintering of MA956 oxide dispersion strengthened steel
}

\author{
Ryan M. Hunt ${ }^{\mathrm{a}, *}$, Kevin J. Kramer ${ }^{\mathrm{a}}$, Bassem El-Dasher ${ }^{\mathrm{a}}$ \\ ${ }^{a}$ Lawrence Livermore National Laboratory, 7000 East Ave, Livermore, CA, 94550, USA
}

\begin{abstract}
Oxide Dispersion Strengthened (ODS) steels' qualities of radiation damage resistance and high strength at high temperature make them promising nuclear structural materials. However, the dispersed yttria that gives ODS steel its beneficial qualities are generally compromised during joining processes, making fabrication difficult and expensive. The selective laser sintering process offers a potential path through this barrier by which net-shape parts can feasibly be built via additive manufacturing without fully melting the structure.

Rastering a $400 \mathrm{~W}$ laser over a $110 \mu \mathrm{m}$ MA956 ODS steel powder bed, we additively built parts with varying build conditions. Although density was achieved to within $97 \%$ of the wrought MA956, ultimate tensile strengths achieved only $65 \%$ of the wrought strength. Spectroscopy analysis points to the agglomeration of the yttria nano-particles as a possible explanation for the loss in strength. Further study might benefit from exploration of other parameters such as thinner powder build layers which would require less energy input to achieve sintering while minimizing time above the melting temperature.
\end{abstract}

Keywords: Additive Manufacturing, ODS Steel, SLS, 3D Printing, MA956

\section{Introduction}

Oxide dispersion strengthened (ODS) steels hold the promise of being extremely high strength, radiation-damage resistant structural materials for the future. However, difficult and expensive fabrication methods currently inhibit wide utilization of these steels. Fortunately, technology advancements in additive manufacturing techniques have recently provided a practical means of potential fabrication of ODS steels.

The additive manufacturing process of selective laser sintering (SLS) is a technique by which components are built up layer-by-layer by sintering a bed of powder into a net-shape. In this process, the ball-milled alloyed powder is loaded onto an elevator supply platform. From the supply powder, a thin layer is scraped across the build platform to await a laser raster that sinters a selected cross-section of the component. The build platform then is lowered incrementally, a new layer is scrapped across, and the laser rasters the next cross section. This process is repeated, building cross-sections layer-by-layer until the full structure is sintered. This process is generally done under an inert gas environment to minimize oxidation of the metallic powder.

The SLS process is attractive as a potential means for creating metal parts without the need for welding, as parts can essentially be made to net shape. This attribute is of particular interest for ODS steels as it could significantly reduce the price associated with prototype or low-number production components. For example, fusion energy components could be significantly cheaper to fabricate via SLS than by conventional ODS steel

\footnotetext{
${ }^{*}$ Corresponding author. Tel.: 925.422.5934

Email address: hunt52@llnl.gov (Ryan M. Hunt)
}

fabrication methods such as HIP or machining, which would require custom tooling for each prototype part. However, the improved structural qualities of ODS steel derive from a dispersion of yttrium oxide nanoparticles which is generally detrimentally affected by welding. These nanoparticles are especially thermally stable which helps to aid strength during high temperature operation but also causes oxide floating and agglomeration during melting of the matrix material [1]. This feature makes fusion welding of ODS steels especially difficult, as weld melt pools tend to have significantly reduced strength [2].

By controlled the power input of the laser during the SLS process, an area can theoretically be locally sintered without excessive melting. This would potentially enable additive manufacturing, while limiting the amount of agglomeration of the yttrium oxide to still maintain the matrix strength. The ideal SLS process for ODS steel would input just enough energy to the powder to encourage coalescence between neighboring powder particles (sintering) but not enough energy to fully melt each particle. If the correct conditions can be found and optimized, this process would locally sinter powder to create a $3 \mathrm{D}$ structure with minimal deleterious effects to the microstructure.

In this study, we have attempted to additively build fullydense bulk parts of MA956 using the selective laser sintering process, while maintaining the favorable nano-properties of the oxide dispersion strengthened steel. A similar effort has been conducted once before on the ODS steel PM2000 whereby selective laser sintering was successfully utilized to build thin walls $[5,6]$. However, this work did not investigate the bulk properties of the material, so it has yet to be seen how the built parts will perform globally. This article reports our method of additive building of ODS steel parts and the corresponding 


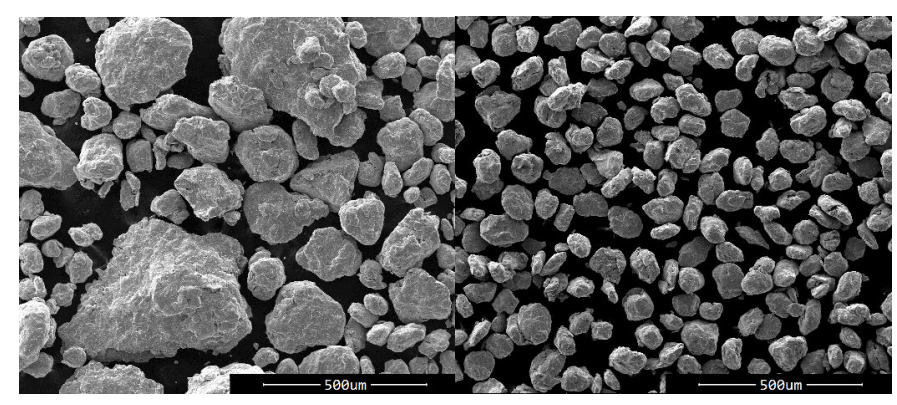

(a) Unfiltered ball-milled MA956

(b) $<110 \mu$ m sieved MA956 powder

Figure 1: Original MA956 powder contained very large particles (a). We sieved this powder to less than $110 \mu \mathrm{m}$ (b) for the additive build supply.

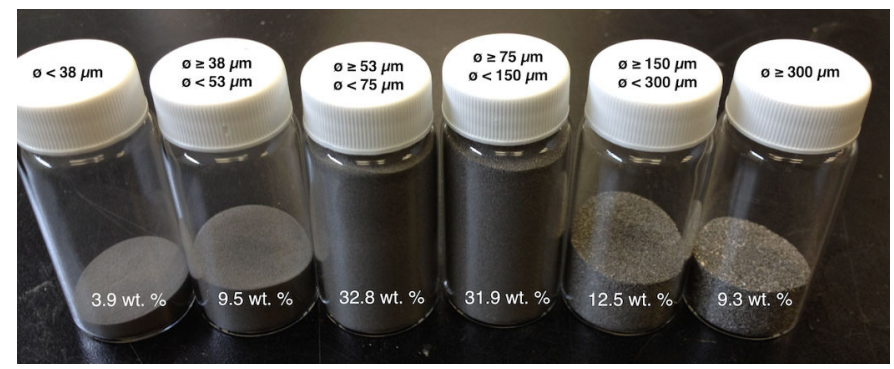

Figure 2: Distribution of powder particle size of as-delivered powder. Based on the success of similar metal SLS studies [4, 5], we included all powders below $110 \mu \mathrm{m}$ diameter.

strength and microstructure obtained.

\section{Experimental Methods}

MA956 steel powder was obtained from Special Metals Corporation as pre-alloyed ball-milled powder with a wide distribution of particle size (see Table 1 for standard composition). To facilitate a uniform build with improved surface roughness and reduced voids, we sieved the particles to leave only particle with a maximum size of $110 \mu \mathrm{m}$ (see Figs. 1 and 2).

From this powder, we conducted an initial build matrix using $400 \mathrm{~W}$ laser printers from Concept Laser to produce 1$\mathrm{mm}$ thick walls while varying three variables: laser power between $240 \mathrm{~W}$ and $360 \mathrm{~W}$, scan speed between $500 \mathrm{~mm} / \mathrm{s}$ and $1000 \mathrm{~mm} / \mathrm{s}$, and trace width between 0.12 and 0.18 (unitless). In all cases, the laser spot size was held at $50 \mu \mathrm{m}$ and powder layer thickness at $80 \mu \mathrm{m}$. See Table 2 for test matrix details.

The twenty-eight walls built from the test matrix were completed on a single plate (Fig. 3a). These were then reviewed under a scanning electron microscope to estimate porosity based on a measurement of the void space in a polished cross-section (using a threshold image technique). Based on these porosity estimates, we selected a subset of parameters from which we would construct larger samples for tensile strength and density measurements.

The second and final build plate was of 15 rectangular prisms on a single plate that would be cut into tensile bars (Fig. 3b). These were ground $0.5 \mathrm{~mm}$ on all sides to remove the significant surface roughness prior to density calculations. Density

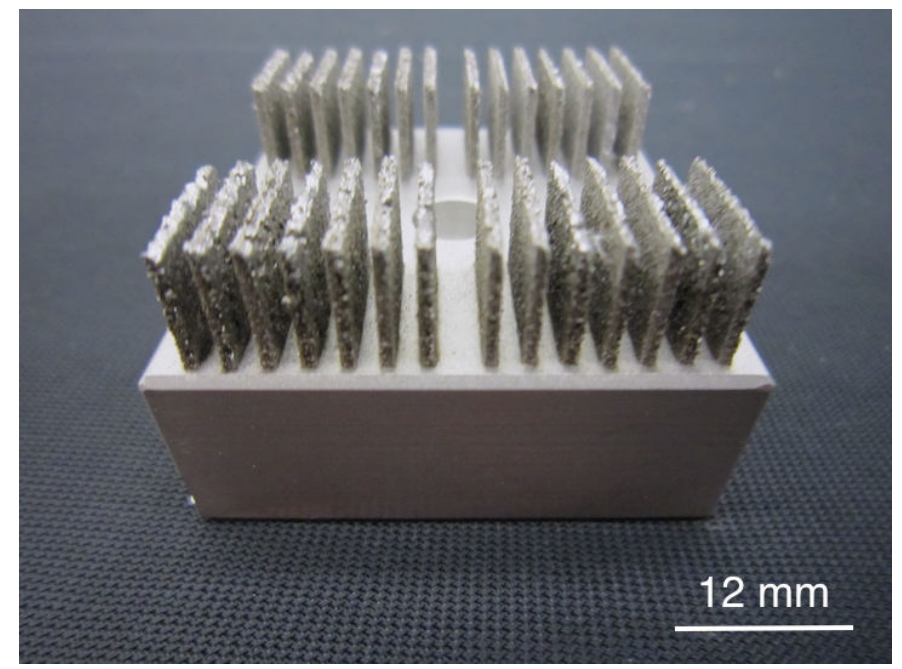

(a) 28 walls built on the initial build plate.

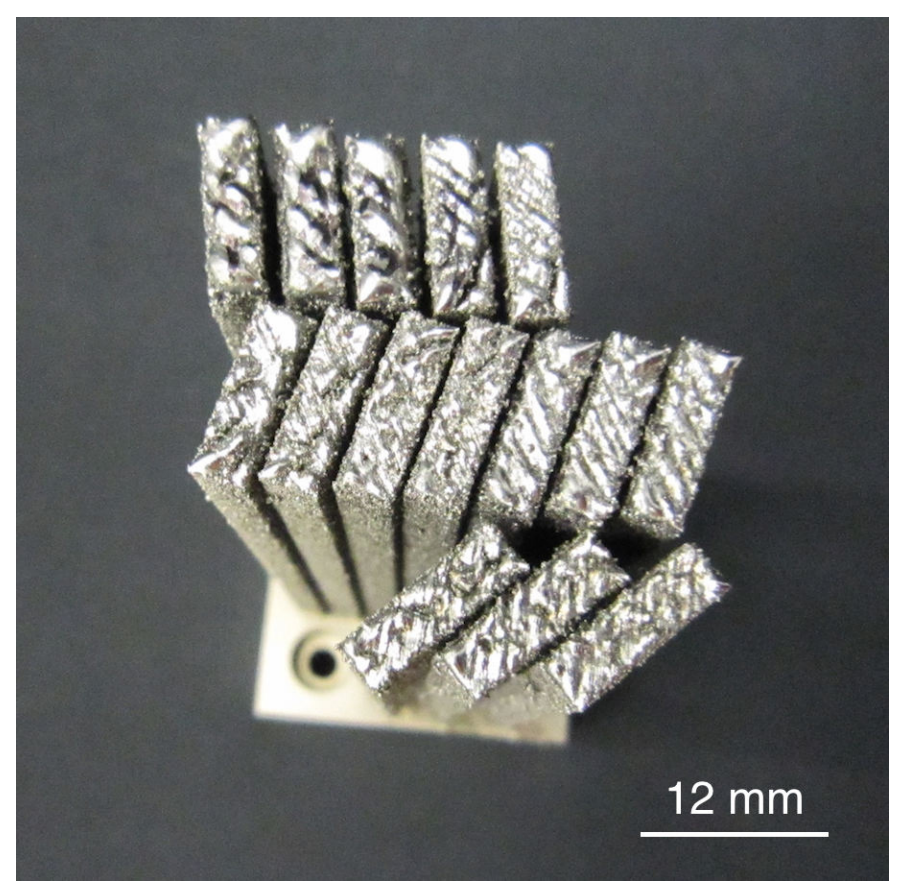

(b) 15 rectangular prisms built on the final build plate.

Figure 3: Initial (a) and final (b) MA956 build plates. Initial plate contained 28 walls with varied laser power, scan speed and trace width. The final plate contained a subset of this with 3 bars each of 5 conditions for density and tensile strength measurement. 
Table 1: Chemical composition of MA956 ODS Steel (wt\%) [3].

\begin{tabular}{lllllllllll}
\hline $\mathrm{Fe}$ & $\mathrm{Cr}$ & $\mathrm{Al}$ & $\mathrm{Ti}$ & $\mathrm{C}$ & $\mathrm{Y}_{2} \mathrm{O}_{3}$ & $\mathrm{Cu}$ & $\mathrm{Mn}$ & $\mathrm{Co}$ & $\mathrm{Ni}$ & $\mathrm{P}$ \\
balance & $18.5-21.5$ & $3.75-5.75$ & $0.2-0.6$ & $<0.1$ & $0.3-0.7$ & $<0.15$ & $<0.3$ & $<0.3$ & $<0.5$ & $<0.02$ \\
\hline
\end{tabular}

Table 2: Test matrix of SLS build parameters, with a $80 \mu \mathrm{m}$ layer thickness and a $50 \mu \mathrm{m}$ spot diameter. Conditions labeled in blue were used for the second iteration of builds (for density and tensile measurement).

\begin{tabular}{lrrr}
\hline Sample & $\begin{array}{r}\text { Power } \\
(\mathrm{W})\end{array}$ & $\begin{array}{r}\text { Speed } \\
(\mathrm{mm} / \mathrm{s})\end{array}$ & $\begin{array}{r}\text { Trace Width } \\
\text { (unitless) }\end{array}$ \\
\hline \#1, \#2, \#3 & 360 & $500,750,1000$ & 0.12 \\
\#4, \#5, \#6 & 360 & $500,750,1000$ & 0.15 \\
\#7, \#8, \#9 & 360 & $500,750,1000$ & 0.18 \\
& & & \\
$\# 10, \# 11, \# 12$ & 300 & $500,750,1000$ & 0.12 \\
$\# 13, \# 14, \# 15$ & 300 & $500,750,1000$ & 0.15 \\
$\# 16, \# 17, \# 18$ & 300 & $500,750,1000$ & 0.18 \\
\#19, \#20,\#21 & 240 & $500,750,1000$ & 0.12 \\
\#22, \#23, \#24 & 240 & $500,750,1000$ & 0.15 \\
\#25, \#26, \#27 & 240 & $500,750,1000$ & 0.18 \\
& & & 0.12 \\
\#28 & 390 & 1200 & \\
\hline
\end{tabular}

was then measured by precision inspection of each bar's mass and volume. Following density analysis, the bars were electron discharge machined down to rectangular tensile bars following ASTM E8 test specifications. These bars were $3 \mathrm{~mm}$ thick, with a gauge width of $5 \mathrm{~mm}$, a gauge length of $25.4 \mathrm{~mm}$, and shoulders $12 \mathrm{~mm}$ wide by $20 \mathrm{~mm}$ long (geometry visible in results section). These bars were then pulled to failure to determine the tensile properties of the various additive build parameters.

To benchmark the resulting tensile and microscopy data, we cut samples from wrought MA956 bar stock for comparison. These produced tensile values to compare to as well as a microstructural basis for nanoparticle analysis. All microscropy was done using a scanning electron microscope with electron dispersive spectroscopy (EDS) and electron backscatter detection (EBSD).

\section{Results}

During the two build iterations, we measured porosity, density and ultimate tensile strength to gage where, if any, optimum build conditions existed. The following section first presents the results of the meclhanical property measurements and then discusses the microstructure differences that could have accounted for the macro-scale mechanical differences.

\subsection{Mechanical property measurements}

\subsubsection{Porosity}

Under a scanning electron microscope, the cross-sectioned and polished wall specimens displayed a variety of porosities

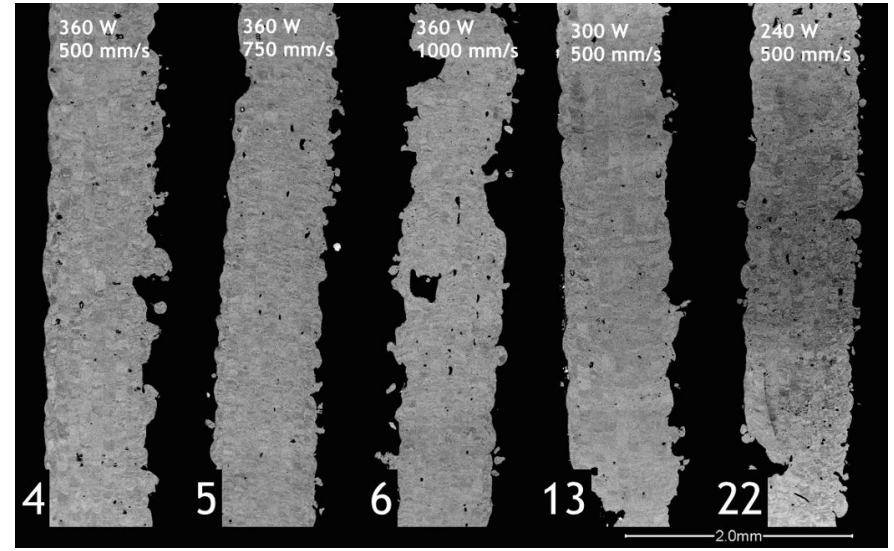

Figure 4: Backscatter electron image of five build conditions. Some porosity is evident, though conditions 4, 5, and 13 appear slightly less porous.

and non-uniformity (see Fig. 4). Conditions 4, 5, and 6 all have the same laser power with varied scan speed, while conditions 4,13 , and 22 have the same scan speed with varied laser power. Together, these five conditions make a representation of the effect of the laser power or scan speed on porosity. All five of these conditions had some degree of porosity, though the worst offenders were \#6 (too fast of a scan speed) and \#22 (too low laser power).

To obtain a qualitative metric for comparing the porosity of all the twenty-eight conditions of the parameter sweep, we have collapsed laser power and scan speed using the equation developed by King, et. al [4]:

$$
\frac{\Delta H}{h_{s}}=\frac{1}{\rho c T_{m}} \frac{A P}{\pi \sqrt{D u \sigma^{3}}}
$$

Where $\rho, c$, and $T_{m}$ are density, specific heat capacity, and melting temperature of the steel, respectively. $A$ is absorptivity, $\mathrm{P}$ is laser power, $D$ is thermal diffusivity, $u$ is dwell time, and $\sigma$ is the spot radius. These values were approximately from the values of stainless steel in the King paper as $\rho=7700 \mathrm{kgm}^{-3}$, $c_{p}=700 \mathrm{Jkg}^{-1} \mathrm{~K}^{-1}, T_{m}=1773 \mathrm{~K}, A=0.4, D=5.38 e-6 \mathrm{~m}^{2} \mathrm{~s}^{-1}$. The spot size for the concept laser system was $r_{\text {spot }}=50 \mu \mathrm{m}$.

Using this metric together with an image analysis of the pores present on the SEM images, a relation immediately presents itself between porosity and normalized enthalpy (Fig. 5). It is clear in this figure that conditions with a lower normalized enthalpy had significantly increased porosity (i.e. either lower laser power or faster scan speed). Once above a normalized enthalpy of 19, however, all conditions resulted in similarly low porosities below $2.5 \%$ and a minimum porosity occurring in sample \#2 of $0.29 \%$. None of the tested conditions appeared to have experienced the keyholing regime as has been seen in SS316L [4]. We hypothesize that higher laser power and/or 


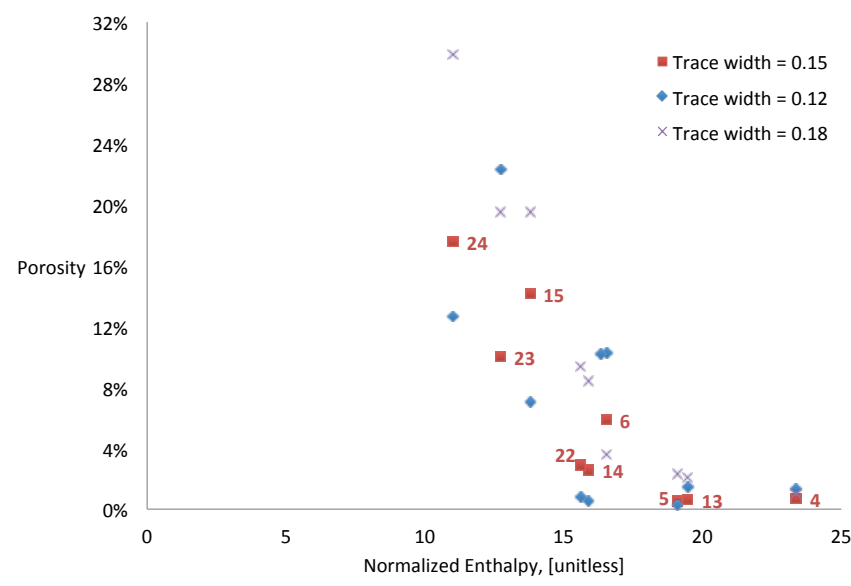

Figure 5: Porosity clearly decreases with increasing normalized enthalpy, a metric recently developed by [4].

lower scan speeds than those tested might result in keyholing to produce the increased porosity similar to the behavior seen in SS316L. However, perhaps this unexplored parameter space could yield interesting results upon further study.

Variation of trace width did not generate any obvious changes in the build, producing no systematic porosity variance. At lower enthalpies, a smaller trace width generally resulted in more favorable low porosities. However, this relation was not true systematically, nor across all enthalpies. As the microstructures of varied trace widths were nearly identical, the second iteration of builds focused only on the center condition, 0.15 , to study the other build variables instead.

\subsubsection{Density}

With respect to normalized enthalpy, density varied in a parabolic trend indicating an optimum normalized enthalpy for this steel. This again echoed the findings of similar productions of SS316L. Perhaps as importantly, all conditions resulted in density very close to the standard MA956 bar stock density. Compared the Special Metals density specification of $7.25 \mathrm{~g} / \mathrm{cm}^{3}$ [3], the best SLS parameter set (\#13) had a density of $7.04 \mathrm{~g} / \mathrm{cm}^{3}, 97 \%$ of the wrought density, while the average density of all the conditions was $6.83 \mathrm{~g} / \mathrm{cm}^{3}$ or $94 \%$ of wrought.

Even after being ground down by $0.5 \mathrm{~mm}$ on every side, the tensile bars still revealed large porosity irregularly distributed between samples. Some of the 15 bars showed on the order of $1 \mathrm{~mm}$ pores on one side, while other bars looked nearly perfect at a macro scale (see Fig. 7 for a snapshot of the best and worst faces of each SLS condition).

\subsubsection{Tensile strength}

The tensile strength of all samples was significantly lower than the wrought MA956 steel (Fig. 8). Compared to the ultimate tensile strength of $995 \mathrm{MPa}$, the best SLS build achieved $\sigma_{U T S}=651 \mathrm{MPa}(65 \%$ of the wrought strength). This reduced strength could possibly have resulted from a few sources, including porosity (the average relative density was $94 \%$ ), or perhaps from differences in one or both of the micro- and nano-

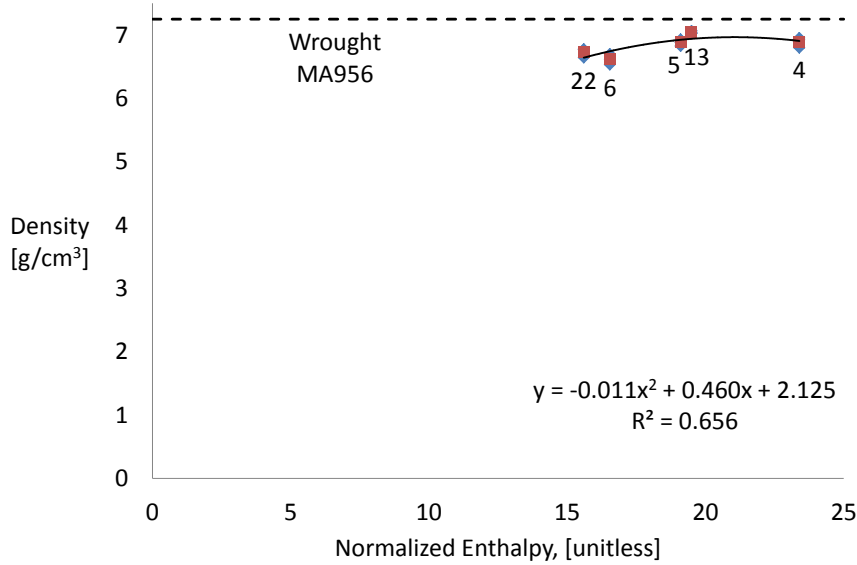

Figure 6: All additively build bars achieved densities approaching the wrought MA956 bar stock. Additionally, a parabolic relationship was apparent with respect to normalized enthalpy, indicating an optimum power input.

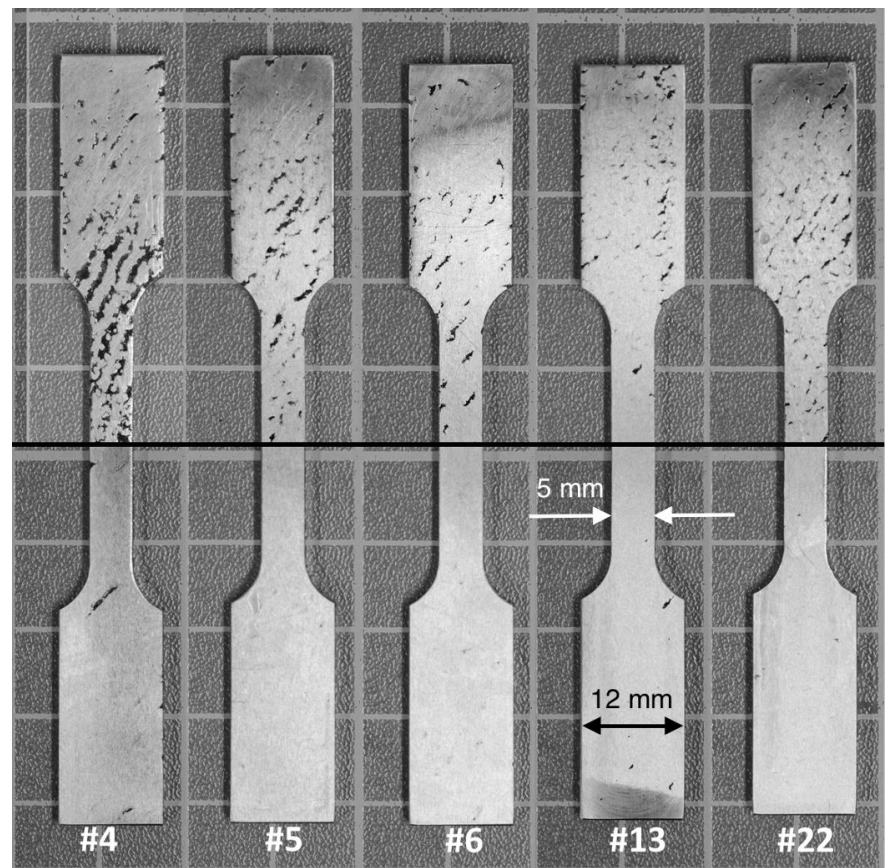

Figure 7: A split image of the best and worst surfaces of each AM conditions. Of the 15 bars printed for density and tensile testing, the worst faces of each conditions still showed significant porosity after a $0.5 \mathrm{~mm}$ surface grind. 


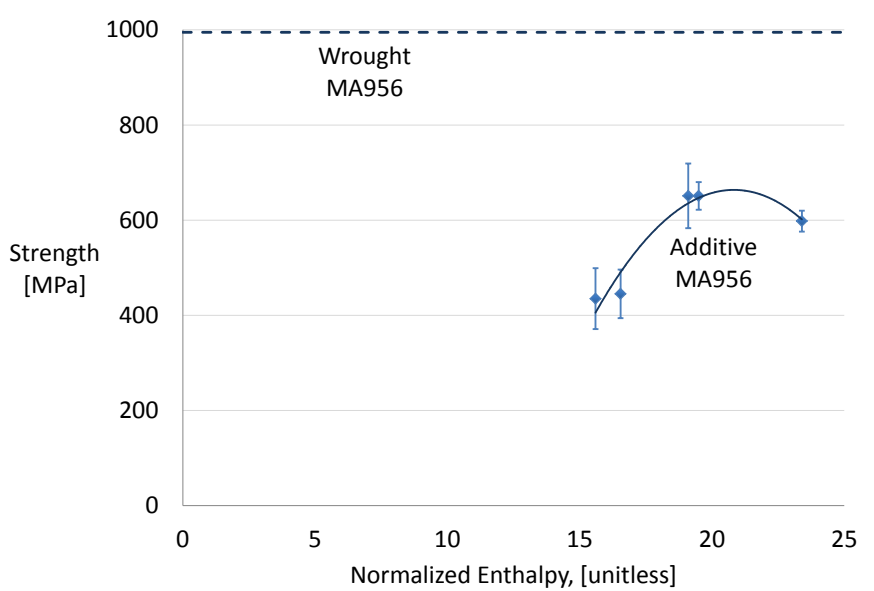

Figure 8: Ultimate tensile strengths of the additively-produced bars are at best only $65 \%$ of that of the bar stock MA956.

structure. Fractured surfaces did reveal that failure often occurred at the site of a particularly large pore (see Fig. 9), indicating that porosity could have had dire effects on the tensile strength. Tensile data of the AM bars had large standard deviation (up to $68 \mathrm{MPa}$ ), which might support this concept. Despite this effect, even the strongest single datum point from the AM bars was of significantly lower strength than the wrought steel, pointing again to the micro- and nano-structure as the source of the strength reduction.

\subsection{Microscopy analysis}

Under the limited range of parameters we were able to investigate, the evenly-dispersed yttria oxide appears to have been compromised. Though TEM analysis was not within the scope of this work, macro- and micro-scale voids appeared prominently throughout every magnification scale, with voids up to $50 \mu \mathrm{m}$ in size (see Fig. 11a \& 11b). In these voids were very strong signals of yttrium and aluminum as collected by EDS (Fig. 11). By contrast, oxide nanoparticles in wrought MA956 steel have a mean size of $8 \mathrm{~nm}$ and a particle density of $9.5 e 19 \mathrm{~m}^{-3}$ [7]. The presence of these bubbles suggest that the yttria floated and agglomerated together in the brief time while the surrounding ferrous matrix was liquid. The wrought MA956 showed no signs of similar yttria signal in voids after identical surface preparation.

The tensile strength data together with the SEM evidence of the void elemental composition suggest that some or all of the nano-dispersion was damaged during the high-power laser passes. This agglomeration appears as prominently in the lower normalized enthalpy conditions as in the higher normalized enthalpies, suggesting that the nano-structure does not survive even when the laser conditions are so low as to cause only partial sintering (and increased porosity). However, under different conditions, perhaps with thinner build layers, it might be possible to sinter particles without damaging nanostructure.

The SLS process produced a similar, overlapping weld pool structure in all parts tested (see Fig. 10 for characteristic structure). In this structure, a standard width associated with the

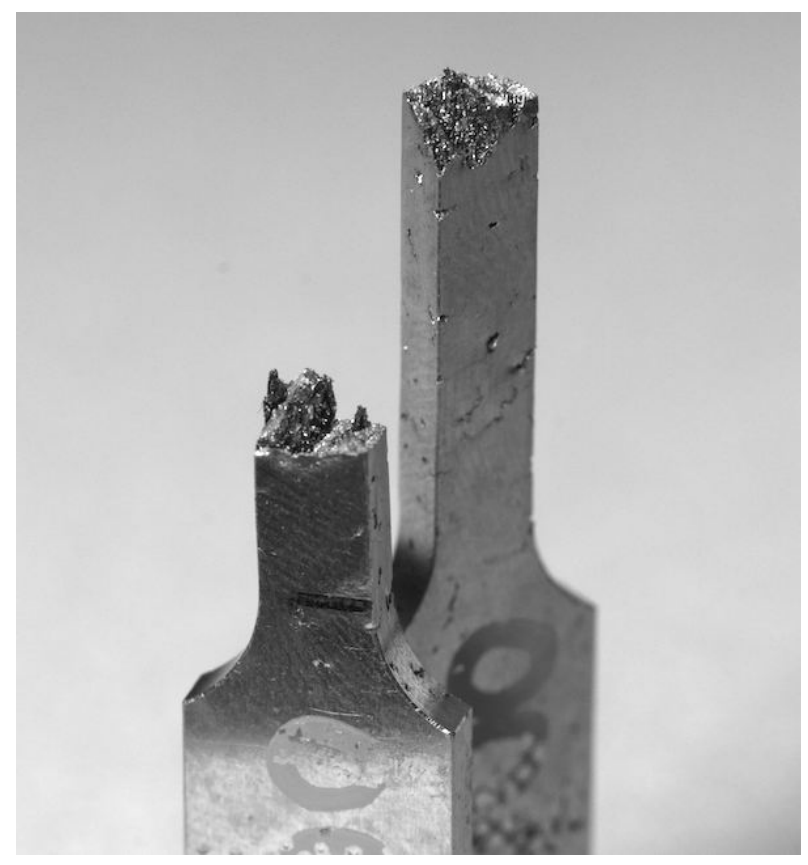

Figure 9: Broken tensile bar surfaces reveal fracture along large pores in the steel, indicating that porosity may have reduced the tensile strength, irregardless of the nano- and micro-structure.

trace width of the condition is evident, but more importantly, melt pools are only $\approx 10 \mu \mathrm{m}$ thick, only $1 / 10$ of the width. This indicates that a given volume of material is getting melted not once, but multiple times. This overlap keeps the material above melt much longer than necessary for sintering and likely adds to the nano-structural damage.

An EBSD grain orientation map of the cross section of a representative run (Fig. 12b) reveals the clear shape of each row of weld pools laid on top of one another. The weld pools solidified in many cases as single grains greater than $70 \mu \mathrm{m}$ wide. This grain structure was similar in all SLS conditions. As an exercise, the material was annealed at $1050{ }^{\circ} \mathrm{C}$ for $1 \mathrm{hr}$ and quenched to measure the effect on the grain structure (Fig. 12c). This seeded a few new grains to roughly halve the size of the weld pool grains, but remained much larger than the wrought grain size and much more non-uniform than the even distribution present in the wrought MA956 (Fig. 12a). Thinner layers with smaller starting powder particle size and lower normalized enthalpy may have resulted in smaller grains with possible higher strength.

\section{Conclusions}

Additively manufactured structures of MA956 ODS steel were produced via selective laser sintering. The parameter sweep of laser conditions showed that there was an optimum power input of about $300 \mathrm{~W}$ at $500 \mathrm{~mm} / \mathrm{s}$ (condition \#13) that lead to the least porosity, highest density, and highest tensile strength. However, all built structures were significant lower strength than wrought MA956, due presumably to the damage inflicted on the nano-structure. Microscopy revealed that there 


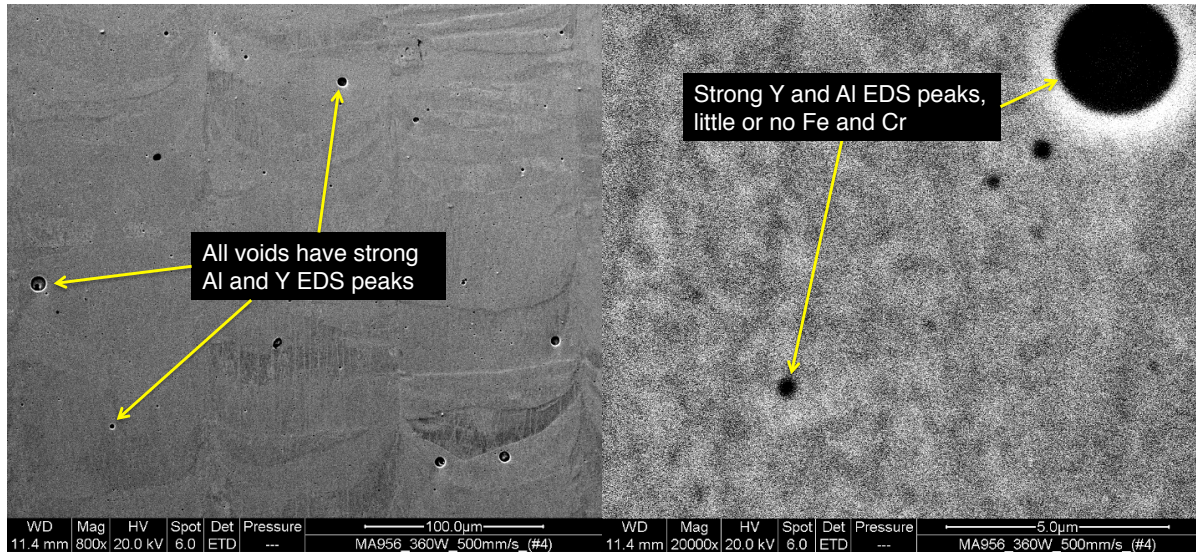

(a) Low-magnification of AM MA956 (b) High-magnification of AM MA956

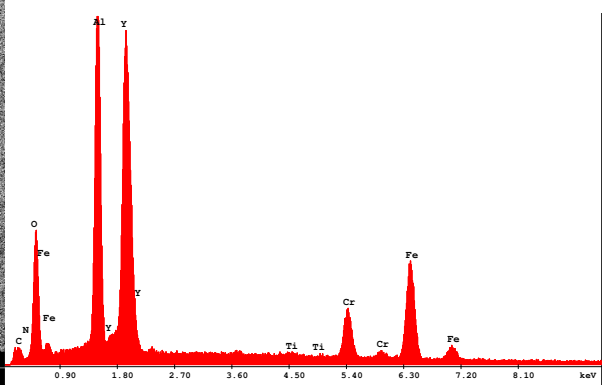

(c) Representative EDS signal of the voids

Figure 11: Voids appear at both low-magnification (a) and high-magnification (b) scales (and everything in between), with strong yttrium and aluminum EDS signals in every void. This indicates that the additive structure has clear agglomeration and floating of oxides during the melting process.

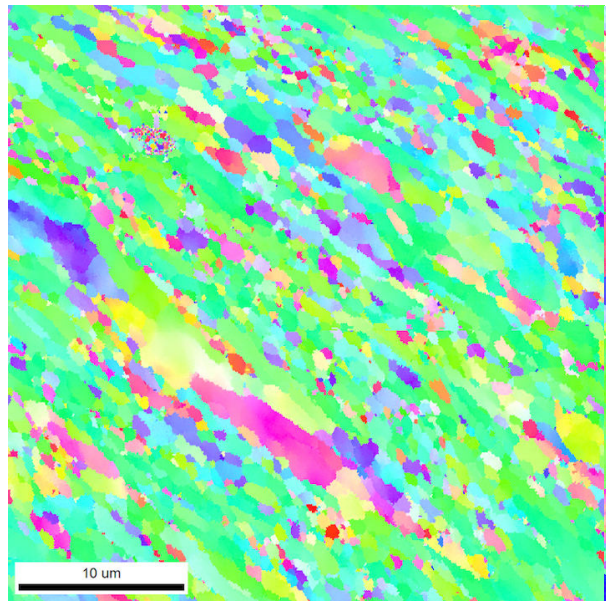

(a) Wrought MA956

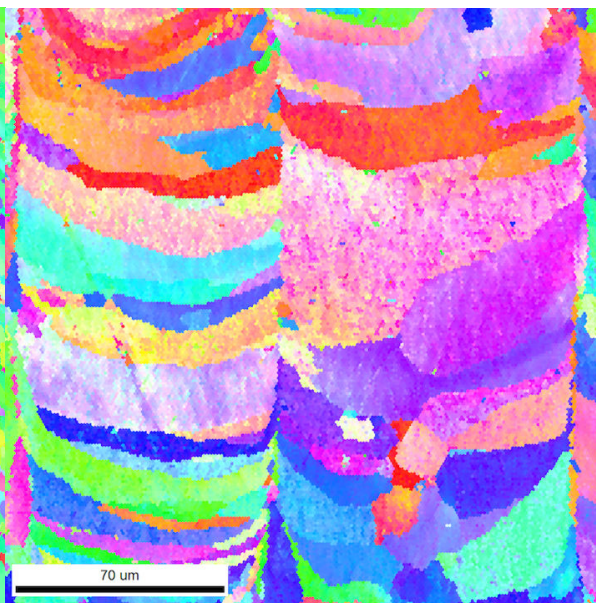

(b) SLS \#6 - 360W, 1000mm/s

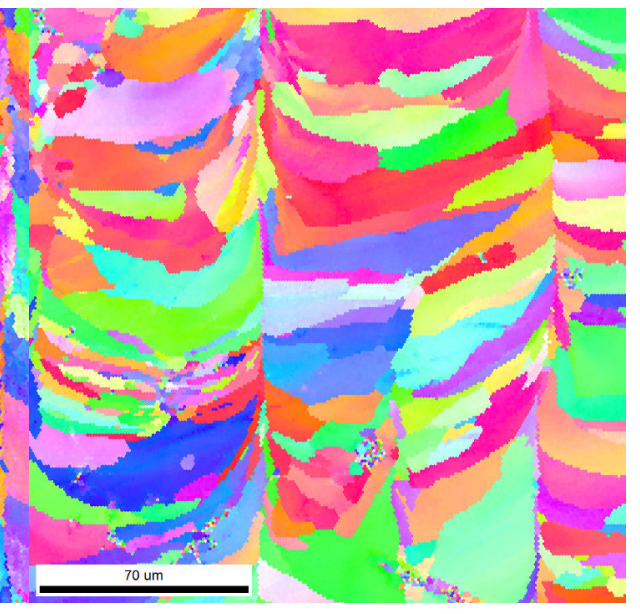

(c) SLS \#6 after annealing @ 1050 C/1hr

Figure 12: The sub-micron grain size of the wrought MA956 (a) was dramatically increased in the weld pools left by the SLS process (b). Annealing at $1050{ }^{\circ} \mathrm{C}$ for $1 \mathrm{hr}$ seeds some new grain growth, but only marginally (c). 


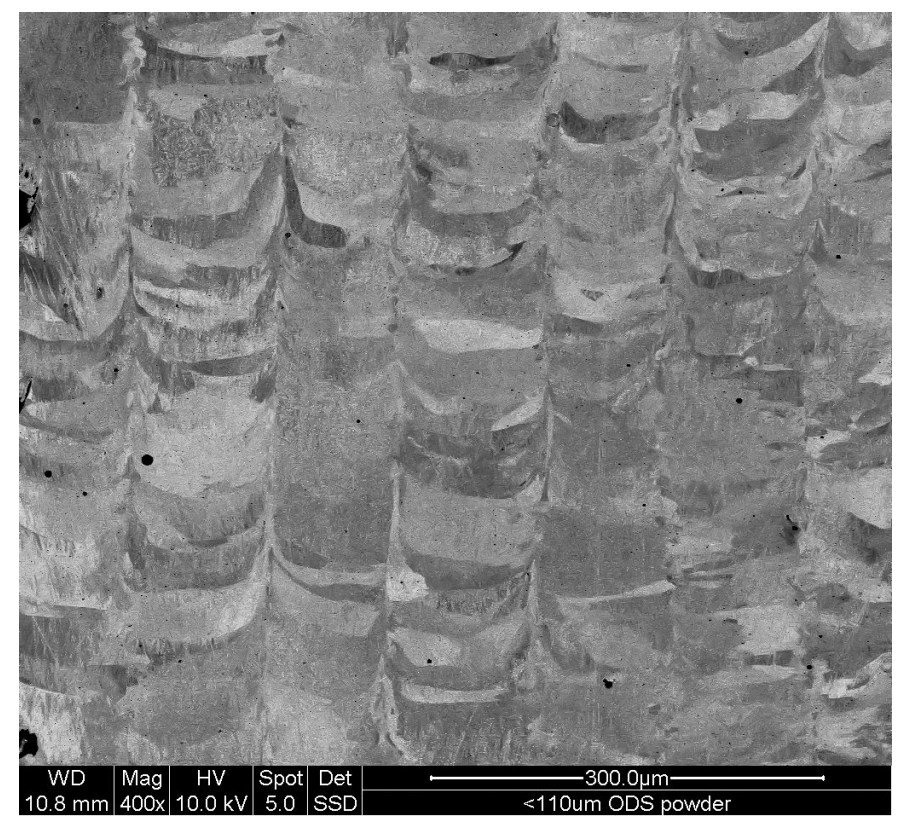

Figure 10: Electron backscatter of a polished cross-section of condition \# 4 $(360 \mathrm{~W}, 500 \mathrm{~mm} / \mathrm{s})$. The melt pools are roughly $100 \mu \mathrm{m}$ width and clearly overlap vertically, indicating that the same material is melted numerous times under successive passes.

was yttrium and aluminum present in large and small void bubbles throughout the material that appear to be the result of agglomeration of the yttrium oxide nanoparticles. Without these evenly dispersed particles, the steel lost much of its former strength.

As has been found in studies that have attempted fusion welding of ODS steel, melting of the material matrix has caused repercussions to the nano-structure. This could potentially be avoided by better heat input control, though it may be difficult to still obtain sufficient void closure. Alternatively, if laser power were kept low enough to intentionally only achieve partial sintering, the part could be HIP'ed as a secondary process steps, while preserving the nano-structure. Given the limited parameter space that was explored in this work, the technology seems promising for development with further effort to further improve strength with better nano- and micro-structural control.

\section{Acknowledgments}

This work performed under the auspices of the U.S. Department of Energy by Lawrence Livermore National Laboratory under Contract DE-AC52-07NA27344.

\section{References}

[1] B. Baker, T. McNelley, L. Brewer, Grain size and particle dispersion effects on the tensile behavior of friction stir welded ma956 oxide dispersion strengthened steel from low to elevated temperatures, Materials Science and Engineering: A 589 (2014) 217-227.

[2] T. Kelly, Pulsed YAG laser welding of ODS alloys, in: Laser-Solid Interactions and Laser Processing-1978: Materials Research Society, Boston, volume 50, AIP Publishing, pp. 215-220.

[3] Incoloy alloy MA956, Special Metals Corporation, 2004.
[4] W. E. King, H. D. Barth, V. M. Castillo, G. F. Gallegos, J. W. Gibbs, D. E. Hahn, C. Kamath, A. M. Rubenchik, Observation of keyhole-mode laser melting in laser powder-bed fusion additive manufacturing, Journal of Materials Processing Technology 214 (2014) 2915-2925.

[5] J. C. Walker, K. M. Berggreen, A. R. Jones, C. J. Sutcliffe, Fabrication of $\mathrm{Fe}-\mathrm{Cr}-\mathrm{Al}$ oxide dispersion strengthened PM2000 alloy using selective laser melting, Advanced Engineering Materials 11 (2009) 541-546.

[6] S. Dryepondt, K. Bimal, G. Tatlock, A. Jones, A. R.-V. Put, Qualification of new commercial ods alloys, 2012.

[7] L. Hsiung, M. Fluss, J. Kuntz, B. El-Dasher, W. Choi, S. Tumey, A. Kimura, Tem study of oxide nanoparticles in ods steels developed for radiation tolerance, 2010 . 